\title{
Epiphany
}

Epiphany: Vol. 6, No. 2, 2013

ISSN 1840-3719

\section{Speech Act Theory: Austin, Searl Derrida's Response and Deleuze's Theory of Order-word} Hasan Baktir

\begin{abstract}
Speech Act is an influential theory on the actual communicative function of language and tries to answer to what extend impartial interaction is possible between speakers. The theory was first developed by Austin and Searl. They argued that order-words have primary meaning and clearly convey the message of the speaker. Derrida challenged the theory and disposed the argument. Using Speech acts and Derrida's disposal, Deleuze and Guattari brought a new perspective to the argument and developed a new ideas different from the ones already existed. This paper aims to discuss to what extent Austen, Searl, Derrida Deleuze and Guattari contributed to the communication theory.
\end{abstract}

Keywords: Speech Acts, Communication, Order-Words, Significance, Iterability

\footnotetext{
* Corresponding author: Hasan Baktir, Assist. Prof. Erciyes University Faculty of Education,Turkey; e-mail: hbaktir@erciyes.edu.tr
} 
Is there safe and impartial communication? Does speech act theory provide us with the solutions to the problems of safe and impartial communication? These are the questions we are going to deal with in the present paper. Firstly, the present paper proposes to discuss Austin and Searl's' theory of speech act, then refers to Derrida's objection. Thirdly, Deleuze and his theory of language and order-words will be discussed referring to the possibility of safe and impartial communication. The research will be descriptive; we will discuss and explain the possibility of safe and impartial communication in the works of Austin, Derrida and Deleuze.

Communication is a function of language and it is carried out by speech in spoken language. Speech is the shorter or longer strings of linguistic items used in order to express particular purpose and includes both written and spoken text. Speech is dependent on the will of the speaker and therefore it is totally individual (Gallaway, 1994: 184). Language on the other hand, is entirely social and changes from one speech community to another. Speech is also social. The communication is a social activity. Speech, being the medium of communication, depends on the linguistic knowledge and competence of the speaker. If a speaker knows the language, he can speak and communicate properly.

There are some rules that regulate and determine the way we communicate. A speaker of the language has to be careful about the quantity. That is, he/she has to make a statement as informative as it is required. When one is asked 'who is that person?', the correct answer would be 'she is Alice, daughter of Mr. Jon'. The uncooperative answer to the question would be 'she is a girl' or 'she is Alice, daughter of Mr. Jon, 15 years old, a university student'. One has to balance his/her speech for a correct communication. The speaker is required to give a true answer to the question. One cannot answer the question above like 'she is Margaret' if she is Alice. The clear answer is another requirement. The answer to the question cannot be 'she is a man'. In addition, one has to order the information when speaking. For instance, the answer to the question 'who is that person' cannot be ordered as 'she is a daughter of Mr. Jon and Alice'. Instead, the ordered answer is 'she is Alice, daughter of Mr. Jones'.

Speech plays many different roles on different occasions. For example, the speech one hears from people shifting furniture 'to you ... now a bit, 
... to right'. This kind of speech controls and directs people's physical behaviour. In a lecture the role of the speech is to influence the thoughts rather than the actions of the listener. Another role of speech is to establish or reinforce social relation to recognize the presence of each other (Di Pietro, 1994: 84). Speech, then, might be used to ask someone to do something, to get information, for the expression of emotion and for its own sake.

One particular approach to the functional classification of speech is based on speech acts. The philosophers and linguists, following the British philosopher J.L. Austin, have developed it. Austin pointed out that the study of meaning should not be concentrated on the bald statement taken out of context because language in speech can be used for many functions such as promises, invitations, and requests and so on. In some cases we use speech to perform an action (Austin, 1975: 375). In English a set of verbs, which Austin termed as performative verbs, enable the speaker, to perform an act by using one of them in the first person present. Examples of such utterances, also called performative utterances, are 'I sentence you to ten years in prison', 'I warn you to obey', 'I beg you to help me.' In these examples, the speaker explicitly performs an act through speaking. What Austin and his followers have tried to provide is to formulate different functions of speech in terms of general theory of social activity. Some forms of speech, even they do not contain explicitly performative verbs, may serve to perform acts implicitly. For example, 'I will come to the meeting' does not actually contain the verb promise but implies that a promise is being made.

The utterance performs an act without explicitly naming it. "An utterance which has the significance of an act is termed an illocutionary act:" (Wolffson, 1989: 30). The speech act theorists refer to the force of utterance when they describe the performing of such on illocutionary act. From this they drive the notion that utterances may have illocutionary force so that they are interpreted as specific kinds of acts. This kind of categorization of speech acts has been very useful to describe the problems in communication and in translation.

Problems of the no translatability of the illocutionary force and indirect speech acts are another point. An indirect speech act is the one in which the form and function do not coincide. 'Can you close the door?' may be an indirect request or may be interpreted as a simple request for 
information. Austin also mentions about Perlocutionary force. In certain cases it is the inherent function of the speech act to explain beliefs. 'He will soon be leaving' can be classified as a promise if one believes at the news. Perlocutionary force concerns the 'effects' of the act whether intended or actual.

Social interaction and speech act are categorized according to their inherent properties and their effect. For instance, there is a distinction between fighting and winning. The concepts used in classifying speech acts will be typical of cultural concepts and they change from one society to the other. Utterances generally serve for more than one function at the same time; therefore, they are not easily classified. Among the speakers of middle-class American English a compliment may serve as a greeting or an expression of gratitude. In addition, utterances may have more than one function and may take several forms. Speech act theory tries to capture all the possible functions of language by classifying the kinds of action that can be performed by speech. Language becomes a chain of utterances defined in terms of speaker's intention and belief and speech is organized in terms of a set of conversational maxims.

The intention of the speaker and the context of utterance are the basics for safe and true communication. But how do people know which speech act is intended, if each act can use the syntactic structure typically associated with one of the other? A possible answer is to specify happiness conditions or felicity conditions- circumstances under which it would be appropriate to interpret something as a particular type of speech act. For example, if a genuine command has been given, the hearer must be physically able to identify the object involved. Even this partial statement of the felicity conditions for commands would probably enable someone to identify 'pick up that book' and 'That book oughtn't to be on the floor' as genuine commands, and 'go jump in the lake!' and 'Gird up thy loins' as pseudo commands. If one can fully identify the felicity condition for each type of speech act, then one is able to move towards safe and impartial communications (Aitchison, 1994: 96).

There are certain circumstances in which speech cannot perform the presupposed effect. Performatives fail when for instance acted by an actor on the stage or introduced in a poem or spoken soliloquy, since we use language in such cases in a special way and we are unserious (Austin, 1975: 380). It is important to be able to make distinctions 
between the happy and the unhappy; between the normal and the parasitic because without these distinctions Speech Act Theory would not be possible. If one could not maintain a general difference between promises made by people playing roles on stage and promises made by the same people off stage, then one could not say that the "promise made off stage did not entail. These utterances will have context that are proper to them (e.g. one says 'I declare you man and wife' at a wedding) (eanglais com/thesis.html). For Searl, distinction is made solely in terms of the utterer's (or writer's) intentions. Initially, this makes his theory look more impoverished than Austin's since the differences between plays and novels, and real life, seem to be more than a matter of what their authors intended. Indeed such differences seem to be textual and contextual (ibid.).

In the fictitious circumstances language is under etiolation which means fictional, pale, quotational, repeatable, parasitical, and therefore never intended to classical-metaphysical procedure. Derrida is critical about the felicity condition and argues that the serious language needs a context and the intention of the speaker who is sincere and genuine. In addition to the intention, the speaker has to follow the procedure. The presence, then, in the speech act theory is at the center. In the speech act theory, as opposed to the serious and appropriate use of language, there is also nonserious language consisting of absence of serious intention. The language is non-serious because it is repeated, quoted, reapplied and taken out of the original context.

Derrida argues that Austin's theory of language surrounds language like a ditch into which any language might fall. He claims that Austin tries to keep language at home and imprisons language into the context. The agony or etiolation that violates the safe and impartial communication becomes the standard case in Derrida, since language in such cases can be cut from the sender and receiver. When the sender and receiver of the speech disappear, the third party can decipher the aberrant. The ditch is deciphered through writing which repeats itself. Repeatability of the utterance undermines the context and produces as many implications as possible. Derrida insists that writing, through citation and grafting, reproduces the context and free the speech from the safe home and prison of Austin: 'Iterability undermines the context as a final governor of the meaning and implies elsewhere the possibility for citation and grafting' (Derrida, 1968: 152). One can lift out a sequence of words from a 
written context and make an extract with it, or one can insert stolen word into other chains of writing. Speech is also iterable, citable and graftable. For instance, the sentence 'my husband and I' can be iterable as 'she began the speech 'my father and I', or as 'last week I said', 'she began the speech' 'my father and I'. Then, speech, like writing, can be cut from its context and from all its presences of its moment of utterance. The effect of speech and the intention of the speaker do not exclude iterability, citation and grafting because repeatability derails the possibility for safe and impartial communication, yet without repeatability there could be no recognizable signs (ibid.).

The iterability derails the context; therefore, there is no certain, clear-cut context of speech. Yet there is still context but the context is no longer at the center that controls the meaning. Likewise, there is still intention but it cannot be completely present in an utterance or in the context. Intention, like context, never governs the entire meaning and system of utterance (Collins and Mayblin, 1996: 51-55). Then, communication means transactions, repetitions, quotation and reinsertion. Communication cannot be taken as a guaranteed, masterable passage of meaning with a proper context and certain intention, since language is non-masterable dissemination, therefore, cannot convey exactly what someone means or thinks.

Derrida sees Austin's characterization of the proper context as ordinary, normal and serious, and thinks that the concomitant exclusion from consideration of non-serious utterances enables conditions of Speech Act Theory. He sees his investigation as showing that this putative foundation and the attempted exclusion of the parasitic are arbitrary and, in fact impossible. He affirms the permanent, structural possibility of parasitism and, as a consequence, the impossibility of Austinian and Searlean Speech Act Theory.

Deleuze and Guattari are post-structuralists. They deal with the underlying structures that enable written and speaking communication within language. They argue that there is an abstract machine within language, which enables to define it as a homogenous system. It is generally accepted that language is informational and communicational. The study of language- linguistics as we call it, is divisionary dividing language into specific parts like syntax, semantic and pragmatics and trying to figure out the system that operates within the language. Each 
pat of language has its own rules and order. Students learn rules and orders to communicate through language. Compulsory education's function is to teach elementary units of language available for communication (Deleuze and Guattari, 1987:135).

Deleuze and Guattari, unlike Austin and Searl, and Derrida, do not take speech act theory as a separate area for investigation. They take the illocutionary use of language within the notion of order-word, and states that both written and spoken language is ordered. In speech, order has three main rules namely, opening, turn taking and closing. A speaker opens up speech with a statement, the listener carries on and the one, who begins, ends the communication. In written language the order is perpetuated through syntax, grammar and Subject+Verb+Object agreement (ibid.).

The structure both in written and spoken language operates through syntagmatic and paradigmatic relations. In syntagmatic relation a sign enters only into association with a certain set of other signs to be grammatically correct and semantically meaningful. For instance 'the man cooks the fish can be syntagmatically restated 'Ali cooks the fish' or 'The fish is cooked by Ali' but not 'The fish cooks man' or 'The cook the fish man'. The first sentences are syntagmatically ordered and grammatically correct but the later statements are syntagmatically wrong-ordered and grammatically incorrect. In a paradigmatic relation a sign has a number of associated meanings and can be substituted by other signs. 'I like tulip or I like roses can substitute for instance, 'I like flower' without changing the category of signs.

Deleuze and Guattari name the process that operates through order-word in spoken and written language as strata and discuss the process of stratification with relation to the notion of subjectification and significance. Subjectification operates as follows; there is a subject of enunciation who expresses himself in the form of specific statements like 'I think ..., I believe ..., or I want ...' . There is another subject what Deleuze and Guattari calls subject of statement. It is the spoken subject 'I' which gains its meaning from the syntactical relation it has with the other words in the sentence. The 'I' of the sentence and the spoken subject are not same. They come together in arbitrary relation through conjugation. Descartes' cogito 'I think therefore I am' is an example for this relation. The first $\mathrm{I}$ is conjugated with 'think' and the second ' $\mathrm{I}$ ' 
refers to the subject of statement. Through conjugation one is subjectified and subjectification allows only thinking and desiring proper to the sense of identity (Goodchild, 1996:148-151). Each citizen learns what he can and cannot do through subjectification and becomes socialized. In this sense education at schools does not 'only instruct the rule of grammar but also gives order and command. The significance is the operation of language as syntagmatic and paradigmatic strata. The function of significance is subjectification.

According to Deleuze and Guattari, the speech acts -as predicated by Austin and Searl for safe and impartial communication and as criticized by Derrida- is what makes subjectification (socialization) possible. Language and statement say very clearly what should be retained. That is, language demands and grammar is a power marker before it is a syntactical marker (Deleuze and Guattari, 1987:83-103). Sociability assumes language and it is likely that it will be organized by signs of imperative kinds like command, judgment, and performative words (Gatens, 1995) that transmit or engender effect and have pragmatic implications.

The meaning and coerciveness of order-word depends upon its socially accepted significance. That is, speech act presupposes social unconscious within the collective assemblage of enunciation. Order-word is functional and conjugates certain socially defined actions and changes the social situation with statements that effectively accomplish them (Deleuze and Guattari, 1987: 85). For instance, 'sit down', 'stop here' do not only operate as command but also function to organize acts, effects, desires and state of affairs depending on situation in which they are uttered; when a judge says 'I sentence you 10 years imprisonment', a defendant may be transformed into criminal.

Deleuze and Guattari do not limit speech act theory within certain situation. They argue that illocutionary use of language may create new kinds of social situation according to the contexts they are used. For instance, 'how could he have said such a thing? I will never trust him again' does not only operate as a question but also delivers a judgment and marks the end of one situation starting the beginning of new and different one. The speaker promises not to enter any social relation with the listener. Every statement refers to further statements. 'Where were you last night?' have different answers for different people; for the 
beloved it may connote 'do not make me feel lonely', for the boss it may refer to order 'tell me', for a friend it may be warning ' don't betray me'. In this sense, sign always refers to other signs and further statements.

The order-word is formed in two ways; conjugation or conjunction. The conjugation is formed by verb 'to be'. In the sentence, 'he is guilty' A is $\mathrm{B}$ and $\mathrm{B}$ defines the limit of $\mathrm{A}$. In the second use of order-word the statement is formed by conjunction 'and'. A Thousand Pleautus (1987) is an example for the second usage where the sentences are not conjugated via signification but by the way in which each sentence acts upon each other to change the meaning and each statement acts as implicit presuppositions for further statements. The proper use of order-word, through conjugation or conjunction, requires linguistic and communicative competence. Language and power subjectify through the proper use of language in written and spoken interaction.

Deleuze and Guattari make a distinction between major and minor use of language and like Derrida, investigate the lines for escape from the ordinary use of order-word. Instead of repeatability or iterability of written language, they argue the predictability of further statements in written and spoken interactions. The predictability of further statements does not restrict enunciation within certain context. When a subject attains linguistic and cultural incompetence and rejects to use the repeated appeal to the same set of order-word, he/she begins to create new text, new order-word and new statements through which language is deterritorialized and the subject of enunciation becomes 'foreigner to one's own tongue'. This is common in literature and in art where minor language is used. Kafka, for instance, uses minor language and deterritorialized major language. The minor use of language is referential and turns the death-sentence, dead metaphor and verdict and gives the subject the warning to flee from the fixed and socially determined and restricted situations. Desire is transformed to its own situation and the outside situation where social unconscious and subject survives becomes standard. The distinction between external and internal circumstances is no longer effective.

According to Deleuze and Guattari, this process is accomplished through signification (syntagmatic and paradigmatic relation) and stratification of the social context. Unlike Austin and Searl -who argue that speech acts are created by certain social institutions and situations, they argue that it 
is language that constitutes certain institutions and situations through signification. However, they agree with Austin and Searl and differ from Derrida in that there is a distinction between parole and langue and speech acts break this distinction within the illocutionary use of language. This is the incorporeal transformation of language Incorporeal transformation is recognizable by its instantaneousness, its immediacy and simultaneity of the statement (Deleuze and Guattari, 1987:86). They argue that judge's statement that transforms the accused into convict is pure instantaneous act in which the body and the sign act together. In such case the action (crime) and passion (penalty) affect the body of the convict. Deleuze and Guattari name this is a process incorporeal transformation. In a common usage there is non-corporeal transformation. For instance, the expression 'I love you' is noncorporeal use of language, since the statement does not affect the body but expresses the attribute of the body (ibid.) whereas, 'ready?' as a statement of question is an example for incorporeal use of language.

It is also argued that the speech acts or illocutionary use of language exists with the presence of other. In the Logic of Sense (1987) Deleuze argues that Robinson's world is one in which the other is absent and as such the prohibitions or commands embedded in order-word are also absent. Robinson is free to compose and command. Order-word, in this sense, expresses a possible world as if it were the only and inevitable world, and an appeal to obey. Interaction between two characters (Ben and Gus) in The Dumb Waiter (1989) by Harold Pinter exemplifies the relation between authority and language (p, 125-29):

Ben. Go and light it.

Gus. Light what?

Ben. The kettle.

Ben. You mean the gas.

Ben. (Powerfully) If I mean go and light the kettle I mean go and light the kettle

Gus. How can you light a kettle?

Ben. Light the kettle! It is a common usage

Gus. I think you have got it wrong.

Ben. What do you mean?

Gus. They say put on the kettle

Ben. Who says? 
Gus. My mother

Ben. Who's the senior partner here, me or you?

Gus. You.

Ben. THE KETTLE YOU FOOL!

Gus. All right, all right.

After a while the invisible but authoritative voice speaks from the tube. Ben says to Gus:

Ben. You know what he said? Light the kettle! Not put on the kettle! Not light the gas! But light the kettle! (p, 140).

The voice most probably belongs to Ben's senior partner who decides for what it is. Austen and Searle and Derrida would interpret the interaction between Ben and Gus as a failure of felicity condition. However, Deleuze and Guattari argue that the subject rejects to use the repeated appeal to the same set of order-word. Gus tries to create a new text, a new orderword, new statements which deterritorialise (1987:4) the language and make the subject of enunciation free. According to Deleuze and Guattari, these kinds of breaks are lines of flight (ibid.,) which give the subject an opportunity to reject the strata. The subject attempts to convey his real desire. Yet the subject is stratified by the authority (invisible machine) which instructs to appeal the rules. There is no way to escape in the ordinary language. Therefore, the subject has to obey the authority and give the required answer(s) (cooperative principles or illocutionary acts) to communicate properly. There is no place to express one's own desire in the strata. The flights of lines (Deleuze and Guattari, 1989:3) exist in literary language which deterritorialises the common language and flees from the fixed and socially determined meanings. If there are lines for flight desires.... are transformed to their own situations and people create opportunity for free and safe communication.

Deleuze and Guattari, like Derrida, think that it is not possible to discover the intention of the speaker or statement, since each statement predicates the former and refers to the further ones (Deleuze and Guattari, 1987). Language distorts the intention of the speaker as they exemplify in A Thousand Pleautus: 
The teacher, at the top of the stairs, asks a question that is passed on by servants who distorts it at each step of the way and the student, below in the courtyard, returns an answer that is also distorted at each stage of the trip back (1987:76).

Derrida claims that the iterability of the utterance derails the channel and the intention is lost. Deleuze and Guattari seem to agree with Derrida. Yet they differ in that they dwell on spoken language and pragmatic function of the statement rather than, written signs. Like Derrida, they claim that there is no certain meaning and reference. Each statement refers to further statements. The sentences 'Jon realizes that Mary is a German', 'Jon does not realize that Mary is a German' predicates and presupposes that 'Mary is a German'. Then, each statement can be cut off from the moment of utterance and can be used in a different context. Each statement has multiple voices and each statement is indirect discourse. In particular, minor use of language unlocks the illocutionary use of language, displaces the context and expresses the existence of different world and possibility for new assemblage of enunciation (Deleuze and Guattari, 1987:78).

\section{References}

Aitchison, J. 1993. Linguistics. London, Sydney: Hodder \& Stoughton.

Austen, J. L. 1975. How To Do Things With Words. Cambridge, Massachusetts: Harvard University Press.

Collins, J and Mayblin, B. 1996. Derrida For Beginner. Cambridge: Icon Books.

Deleuze and Guattari. 2005. A Thousand Plateaus. Minnesota: University of Minnesota Press.

Derrida, J. 1968. Difference. In Derrida, Margins of Philosophy.

Di Pietro, R. J. 1994. Strategic Interaction. Cambridge: University Press. Gallaway, C. 1994. Input and Interaction in Language Acquisition. Cambridge: University Press.

Goodchild, P. 1996. Deleuze and Guattari, An Introduction to the Politics of Desire. London: Sage Publications.

Pinter, H. 1991. The Dumb Waiter. London: Faber and Faber.

Wolfson, N. 1989. Perspectives in Sociolinguistics and TESOL. Boston: Heinle and Heinle Publisher. 